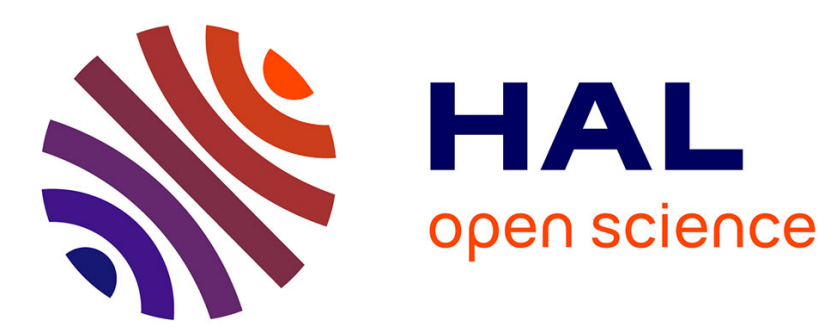

\title{
EAS experiment on board of the Airbus A380
}

J.N. Capdevielle, F. Cohen, K. Jedrzejczak, B. Szabelska, J. Szabelski, T. Wibig

\section{To cite this version:}

J.N. Capdevielle, F. Cohen, K. Jedrzejczak, B. Szabelska, J. Szabelski, et al.. EAS experiment on board of the Airbus A380. XIII International Symposium on Very High Energy Cosmic Ray Interactions at the NESTOR Intitute, Sep 2004, Pylos, Greece. pp.414-417, 10.1016/j.nuclphysbps.2005.07.074 . in2p3-00023773

\section{HAL Id: in2p3-00023773 https://hal.in2p3.fr/in2p3-00023773}

Submitted on 16 Feb 2005

HAL is a multi-disciplinary open access archive for the deposit and dissemination of scientific research documents, whether they are published or not. The documents may come from teaching and research institutions in France or abroad, or from public or private research centers.
L'archive ouverte pluridisciplinaire HAL, est destinée au dépôt et à la diffusion de documents scientifiques de niveau recherche, publiés ou non, émanant des établissements d'enseignement et de recherche français ou étrangers, des laboratoires publics ou privés. 


\title{
EAS eperimen $t$ on board of the Airbs A380
}

\author{
J.N. Capdevielle ${ }^{\text {* }}$, F. Cohen ${ }^{\mathrm{a}}$, K. Jȩdrzejczak ${ }^{\mathrm{b}}$, B. Szabelska ${ }^{\mathrm{b}}$, J. Szabelski ${ }^{\mathrm{b}}$, T. Wibigbc \\ ${ }^{\text {a} P C C, ~ C o l l e ̀ g e ~ d e ~ F r a n c e, ~ 11, ~ p l . ~ M . ~ B e r t h e l o t, ~} 75231$ PARIS Cedex 05, France \\ ${ }^{\mathrm{b}}$ The Andrzej Soltan Institute for Nuclear Studies (IPJ), Cosmic Ray Laboratory, \\ 90-950 Łódź 1, P.O.Box 447, Poland \\ ${ }^{c}$ Dept. of Experimental Physics, University of Lódź, Poland
}

\begin{abstract}
We consider taking the opportunity of about 10.000 hours of test flights of the Airbus A380, and to install at passenger space detectors for high energy cosmic ray events. The altitude of $10 \mathrm{~km}\left(250 \mathrm{~g} / \mathrm{cm}^{2}\right)$ would give opportunity to measure EAS originating from heavy primaries to energies exceeding $10^{7} \mathrm{GeV}$, and also coming without interaction proton component beyond the energy of the knee. At the flight altitude the iron originated EAS are well developed and registering their lateral distribution in 70 meters long cabin it is possible to distinguish them from proton originated EAS. Hadron component of EAS (registered as number of secondary hadrons produced in the detector) would help in discrimination and energy estimation. On another hand, registrations of high energy protons (without EAS) would enable to measure high energy proton spectrum. The energy of the proton would be estimated via hadron multiplicity in single interaction inside the detector. We propose to use about 60 modules of $0.5 \mathrm{~m}^{2}$ of active detectors with scintillators to detect E-M component and carbon target with lead layer to detect the hadronic component via neutron registrations.
\end{abstract}

\section{INTRODUCTION}

The knowledge of energy spectrum and mass composition of Cosmic Rays in energy range $3 \cdot 10^{14}-1 \cdot 10^{16} \mathrm{eV}$ and beyond is still too poor. Therefore the opportunity to perform CR registrations at the level of $250 \mathrm{~g} / \mathrm{cm}^{2}$ is very attractive. The opportunity might be provided by the Airbus A380 with its double level cabins $70 \mathrm{~m}$ long and $7 \mathrm{~m}$ wide. The airliner shall fly $5000-$ 10000 hours without passengers to perform tests required for necessary certificate.

At the $10 \mathrm{~km}$ level (about $250 \mathrm{~g} / \mathrm{cm}^{2}$ atmospheric pressure) some CR protons might come to airplane level without interaction (assuming the interaction length of $\lambda=110 \mathrm{~g} / \mathrm{cm}^{2}$ the probability equals to $\exp (-250 / 110)=0.103$, assuming $\lambda=80 \mathrm{~g} / \mathrm{cm}^{2}$ surviving probability is 0.044$)$. Development of EAS induced by CR protons is strongly dependent on the first interaction level, and therefore such EAS would be very difficult

\footnotetext{
*This work was supported by the IN2P3 Polish-French collaboration between IPJ (Lodł and PCC-CdF (Paris).
}

to analyse. However iron induced EAS (about $18 \mathrm{~g} / \mathrm{cm}^{2}$ interaction length; surviving probability $\exp (-250 / 18)=10^{-6}$ ) are quite well developed and with regular lateral distribution at $10 \mathrm{~km}$ level.

We propose a method to distinguish between EAS produced by the heavy CR component from those produced by protons. For heavy component we would be able to estimate the primary particle energy with usual accuracy. We would not be able to determine primary energy for proton induced EAS. We propose the set of detectors which in principle would allow to register high energy noninteracting protons (i.e. particles without EAS signals from the array) and estimate their energy, as well as register the $\mathrm{E}-\mathrm{M}$ charged component of EAS.

\section{CONSTRUCTION OF THE ARRAY}

The system of detectors to be used on board of airliner A380 during test flights should be optimized to realize two tasks: EAS registration and 
single proton detection (i.e. hadron energy measurement). It should also fulfil Airbus test flight requirements. We plan to register lateral distribution of the soft EAS component and to measure energy of single energetic hadron. This should enable to study iron (heavy) CR spectra up to $\sim 10^{7}$ $\mathrm{GeV}$ and high energy protons surviving without interaction. We propose a set of detector units distributed throughout the airplane. Each unit (see Fig. 1) would consist of (from top to bottom):

- scintillator layer to register single charged particle,

- $40 \mathrm{~cm}$ of carbon (one interaction length),

- scintillation counter (for single hadron trigger: no EAS, single or none particles in top scintillator, and large number of charged particles in this scintillator),

- neutron detector (5 $\mathrm{cm}$ of lead surrounded by moderator and helium counters) to register hadron multiplicity (via neutron production in lead).

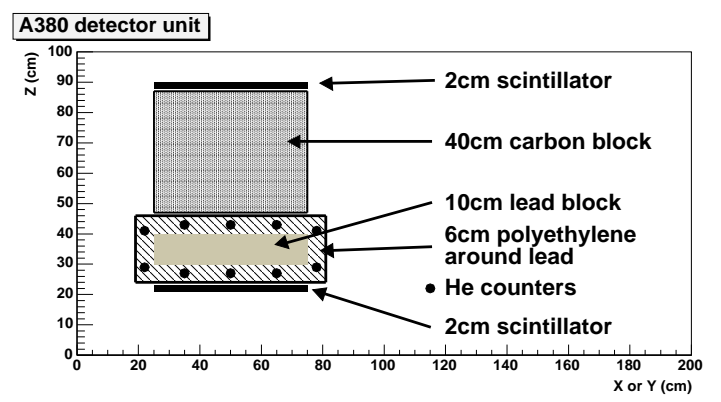

Figure 1. Detector unit to be placed in passenger cabin of A380 airliner for CR measurements.

The total height of the unit would be about 70 $\mathrm{cm}$. One unit of dimensions $50 \mathrm{~cm} \times 50 \mathrm{~cm}$ might weigh about $500 \mathrm{~kg}$ what allows for up to about 160 detectors on board.

\section{ELECTROMAGNETIC COMPO- NENT OF EAS AT 10 KM LEVEL.}

For EAS simulations the CORSIKA code v. 6.030 (21 January 2004) was used. Simulations were performed for vertically arriving protons and iron nuclei. The primary energies were from
$10^{5} \mathrm{GeV}$ to $10^{8} \mathrm{GeV}$ every decade of energy. The EGS and QGSJET model (with CORSIKA QGSJET01) were used. Thinning was applied for particles below $1 \mathrm{GeV}$, however the maximum weight for hadrons was limited to 1 .

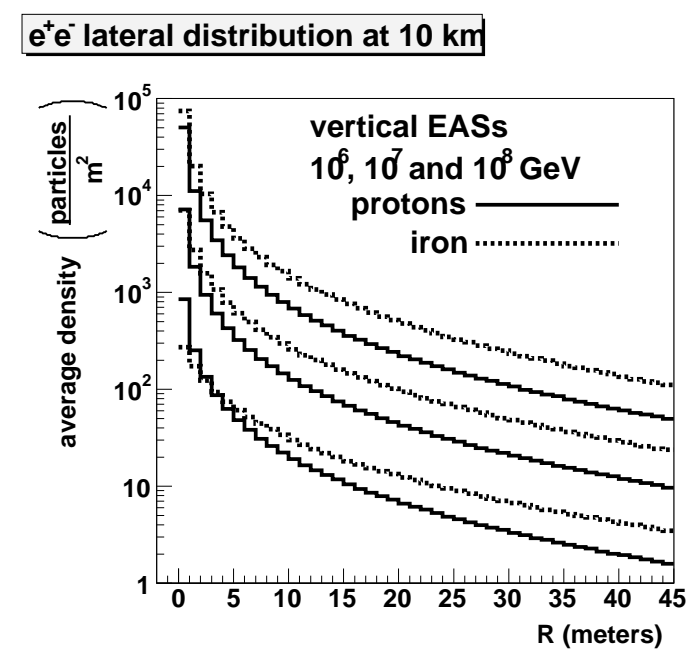

Figure 2. Average density of $e^{+} e^{-}$distribution for proton and iron primaries at $10 \mathrm{~km}$ altitude for vertical showers.

Average $e^{+} e^{-}$density distribution at the $10 \mathrm{~km}$ level from vertical EAS is shown in the Fig. 2. For the average lateral distribution iron induced EAS are larger in $e^{+} e^{-}$component and the distribution is flatter than for proton induced EAS. The gamma lateral distribution have similar properties to $e^{+} e^{-}$distribution, namely the average gamma distribution is wider for iron primaries than for proton primaries.

\section{IRON - PROTON SEPARATION}

From the Fig. 2 we noticed different steepness of $e^{+} e^{-}$lateral distributions for proton and iron primaries. Measuring a parameter which would relate to the steepness of lateral distribution and will be independent from the $N_{e}$ - EAS size might allow to separate heavy $\mathrm{CR}$ originated events. For each shower we define the ratio of sum of densities in the inner part to that in outer part of Fig. 2:

$R_{\text {in } / \text { out }}=\frac{\sum_{i=i n_{1}}^{i n_{2}} \varrho_{i}}{\sum_{i=\text { out }_{1}}^{\text {out } \ell_{2}} \varrho_{i}}$ 
For $\left(i n_{1}-i n_{2}\right)$ equal to $(1-5 \mathrm{~m})$ and $\left(\right.$ out $_{1}-$ out $\left._{2}\right)$ equal to $(20-30 \mathrm{~m})$, the $R_{\text {in } / \text { out }}$ for separate EAS and for average lateral distribution (Fig. 2) we obtained distributions presented in the Fig. 3. For a fixed primary energy the separation is relatively good: only small fraction of proton induced events have a ratio in the iron EAS range. Figures 3 and 4 present iron/proton separation.
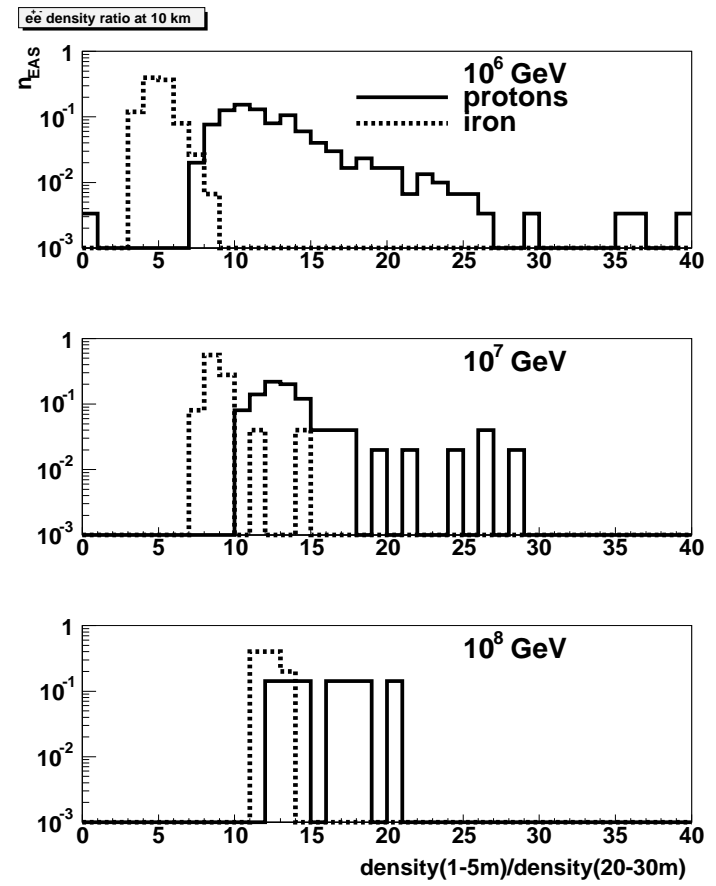

Figure 3. Ratio of sum of densities for the range $1-5 \mathrm{~m}$ to that in the range $20-30 \mathrm{~m}$ from the core (for $e^{+} e^{-}$distribution average for each single EAS). $R_{\text {in } / \text { out }}$ defined as in equation 1.

\section{MODELS OF CR SPECTRA AND EX- PECTED STATISTICS}

As a reference parametrization of Cosmic Ray energy spectra we have taken a paper by J.R. Horandel[1]. We used parameters as in the formula:

$$
\frac{d \Phi_{Z}}{d E_{0}}\left(E_{0}\right)=\Phi_{Z}^{0} \cdot E_{0}^{\gamma_{Z}} \cdot\left[1+\left(\frac{E_{0}}{\hat{E}_{Z}}\right)^{\epsilon_{c}}\right]^{\frac{\gamma_{c}-\gamma_{Z}}{\epsilon_{c}}}
$$

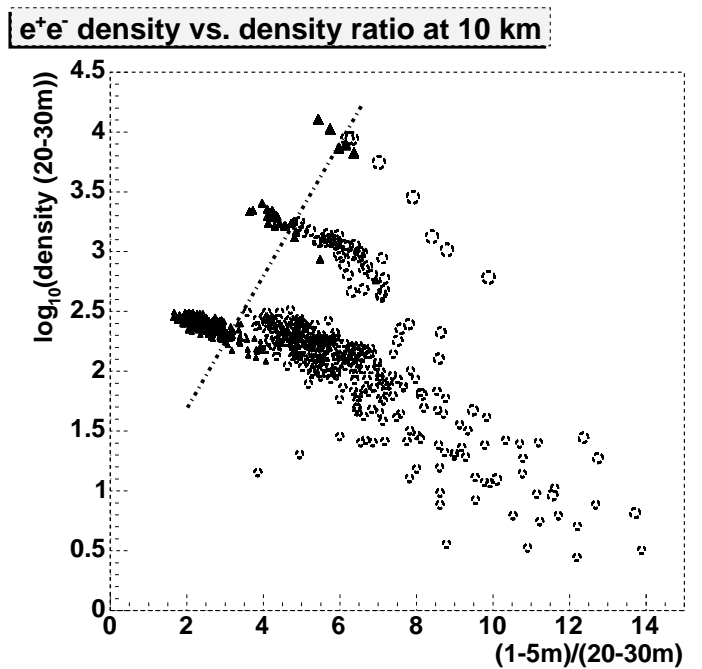

Figure 4. $\log _{10}$ (summed densities in the range $20-30 \mathrm{~m})$ vs. ratio of sum of densities for range $1-5 \mathrm{~m}$ to that in the range $20-30 \mathrm{~m}$ from the core. Filled triangles are iron showers and open circles are proton induced EAS for primary CR particle energies $10^{6}, 10^{7}$ and $10^{8} \mathrm{GeV}$. Line limits proton area. Most of iron induced EAS can be separated from proton induced EAS.

For the purpose of these calculations we used for protons fit for $\mathrm{Z}=1$, for $\alpha \mathrm{Z}=2$, for $\mathrm{CNO}$ sum for $Z=6,7,8$, for $A=28$ sum for $Z=10-16$ (both included), and for $\mathrm{Fe}$ sum for $\mathrm{Z}=20-26$ (both included). We use 3 modes: mode $=1$ for knee at constant rigidity, i.e. $\hat{E}_{Z}=E_{p} * Z$ (called rigidity dependent knee), mode $=2$ for knee at constant energy per nucleon, i.e. $\hat{E}_{Z}=E_{p} * A$ (called mass dependent knee), and mode $=3 \hat{E}_{Z}$ $=E_{p}$, i.e. knee at constant energy. Intergrated Cosmic Ray spectra for 3 models of the knee are presented in the Figure 5. The 1 EAS limit corresponds to exposure of 5000 hours (208 days), $60 \mathrm{~m} \times 6 \mathrm{~m}$ of EAS core area, and the zenith angle limit of about $23^{\circ}(0.5 \mathrm{sr})$. The 1 surviving proton limit was evaluated for the same time, 100 of $0.5 \mathrm{~m}^{2}$ detectors, for $1 \mathrm{sr}\left(\vartheta<33^{\circ}\right)$ and for $10 \%$ chance for proton to survive without interaction to the $10 \mathrm{~km}$ altitude.

Expected unaccompanied proton number and EAS number of $\mathrm{CR}$ iron origin for different $\mathrm{CR}$ 
spectra are shown in Table 1.

Table 1. Expected unaccompanied proton number and EAS number of CR iron origin for different $\mathrm{CR}$ spectra.

\begin{tabular}{|r|c|c|c|}
\hline \hline \multicolumn{4}{|c|}{ expected surviving } \\
proton number \\
\hline \hline energy & rigidity & mass & energy \\
\cline { 2 - 4 }$(\mathrm{GeV})$ & \multicolumn{3}{|c|}{ dependent knee } \\
\hline $10^{5}$ & 1700 & 1700 & 1700 \\
$3.2 \cdot 10^{5}$ & 240 & 240 & 240 \\
$10^{6}$ & 30 & 30 & 30 \\
$3.2 \cdot 10^{6}$ & 3.1 & 3.1 & 3.1 \\
$10^{7}$ & 0.3 & 0.3 & 0.3 \\
\hline \hline \multicolumn{4}{|c|}{ expected EAS number } \\
of CR iron origin \\
\hline \hline energy & rigidity & mass & energy \\
\cline { 2 - 4 }$(\mathrm{GeV})$ & dependent knee \\
\hline $10^{6}$ & 910 & 910 & 760 \\
$3.2 \cdot 10^{6}$ & 150 & 150 & 84 \\
$10^{7}$ & 23 & 24 & 7.8 \\
$3.2 \cdot 10^{7}$ & 3.1 & 3.6 & 0.7 \\
$10^{8}$ & 0.3 & 0.5 & 0.06 \\
\hline
\end{tabular}

\section{CONCLUSIONS}

We propose to install on board of the Airbus A380 an array of compact detectors capable to register Cosmic Rays with energies around the "knee". The array would allow to measure:

- heavy component energy spectra up to several times the knee energy with the discrimination between different models of mass composition above the "knee",

- proton component (as registration of particles surviving without interaction) up to the knee region.

\section{REFERENCES}

1. J.R. Horandel "On the Knee in the Energy Spectrum of Cosmic Rays", astro-ph/0210453 (20 Oct. 2002).
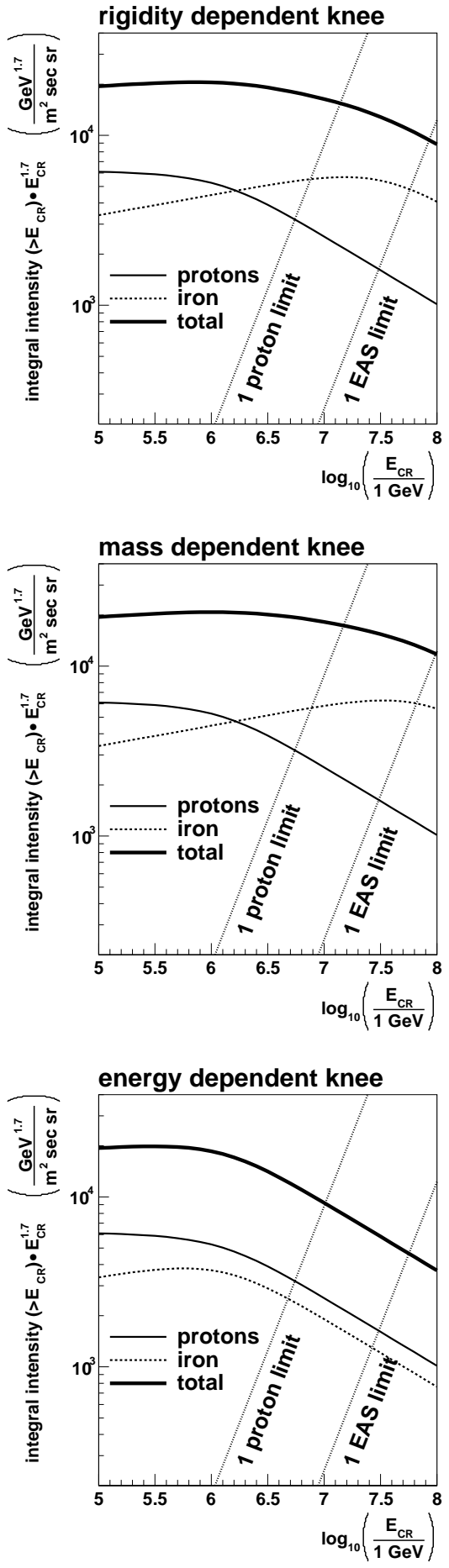

Figure 5. Exposure limits for different CR spectra models. 